\title{
Vacancies and Attenuated Presences: A counter-memorial swimming pool for Waitara
}

\author{
Keywords \\ Counter-Memorial, Landscape, Memorials, Spatial Design, Witness.
}

Memorials are witnesses to histories, places and people long past. Their utterances can be felt, and heard, if one is in a place to listen. Memorials are progenitors of these voices, functioning as curious and controversial locative markers. This paper reports on a practice-led inquiry into the memorial swimming pool. It presents these strange and disjunctive spaces as countermemorials, media for alternative methods of remembrance. The project unfolded across two stages: documentary fieldwork, and a speculative design intervention. The fieldwork consisted of expeditions to three memorial swimming pools found across Te Ika-a Maui, the North Island of New Zealand. These are located in Manutahi, Otorohanga and Clive. Methods of site-specific inhabitation and witnessing, such as drawing and site-recording identify, and accrete the phenomenal language of these sites. This involves particular observation towards presences and absences. The work refers to Michael Taussig in his observations that field recordings such as drawings, exist as 'more than the result of seeing'. They present opportunities for a different kind of optic. Philosopher and critic Walter Benjamin's concept of the dialectical optic is explored in how these sites allow us to 'perceive the everyday as the impenetrable, and the impenetrable as the everyday'. Transient and mundane images were investigated as counter-memorial markers, and as evidence of changing roles, temporalities, and ecologies. Travel, the fieldworker's approach and temporary inhabitation, is considered as a part of the fieldwork methodology of the project, both in a practical and temporal sense. The fieldwork developed a conversational understanding of place through considering the past, present, and future landscapes we occupy in relation to one another. The speculative design intervention leverages the affectual language developed in the fieldwork to propose a reconfiguration of the Waitara Swimming Pool as a counter-memorial. The work comprises a series of mnemonic provocations detailing loss, vacancy, and the crossing of ritual thresholds. These are explored through a speculative architectural work, which assembles images and functions of the collected fieldwork sites. The images of these surfaces and spaces derive from inhabitation, and activity, rather than detached contemplation. They are lived memorials. The body becomes an essential force within the site, and causes the scheme to function more as a memorial landscape rather than a series of obelisks. This engages more with non-western ideologies of memorial, the individual, and landscape. Philosopher Dr Carl Mika refers to this bond being 'indivisible', and that Māori for example; are connected through an 'imprinting upon the landscape'. Conscious and subconscious movements position the viewer as an active participant rather than a distanced observer. Both the present and the absent body are critical to the formal and thematic composition of each encounter presented to the viewer. Vertical and horizontal cuts form frames and floors which are inhabited or made void by the body. Through ecological conditions, and as the pools are used, these cuts generate new reflective surfaces and offer viewpoints. My work imagines ways to localize memories and stories through immersion in a new countermemorial landscape, presenting opportunities to inhabit attenuated memory. 